\title{
Use of autologous platelet-rich plasma for a delayed consolidation of a tibial fracture in a young donkey
}

\author{
Vanessa FAILLACE ${ }^{1)}$, Adolfo Maria TAMBELLA ${ }^{1) *}$, Margherita FRATINI ${ }^{1)}$, \\ Emanuele PAGGI ${ }^{1}$, Fabrizio DINI ${ }^{1)}$ and Fulvio LAUS ${ }^{1)}$ \\ ${ }^{1)}$ School of Biosciences and Veterinary Medicine, University of Camerino, Via Circonvallazione, 93/95, 62024 \\ Matelica, MC, Italy
}

J. Vet. Med. Sci.

79(3): 618-622, 2017

doi: 10.1292/jvms.16-0400

Received: 6 August 2016

Accepted: 24 January 2017

Published online in J-STAGE:

13 February 2017
ABSTRACT. A 9-month-old filly donkey was referred for a comminuted diaphyseal fracture of the right tibia. Surgical osteosynthesis, with multiple lag screws and a neutralization plate, was performed for anatomical reconstruction. Despite a good gait condition, delayed bone consolidation and a bone gap were evident on follow up radiographic evaluations. Due to delayed healing, autologous platelet-rich plasma (PRP) was injected on the surface of the tibia. Increased bone consolidation was evident on radiographs one month after the PRP injection. Progressive filling of both the fracture lines and bone gap continued during the six-month follow up. Clinical outcome was excellent. Autologous PRP should be considered as a practical adjuvant therapy in bone healing process in donkeys.

KEY WORDS: bone, donkey, platelet-rich plasma, regenerative therapy, tibial fracture

Equine tibial fractures are uncommon and often secondary to external trauma [4]. Tibial fractures are most often diaphyseal and comminuted and have a spiral configuration. The incidence of tibial fractures in horses has not been definitely established [16], and less is known about tibial fractures in donkeys [10].

Non-transfusional hemocomponents are reported to be effective in restoring normal function and structure in the musculoskeletal system after injury or damage $[14,19]$. The use of blood-derived biomaterials for tissue healing and therapeutic purposes offers a safe and interesting alternative to conventional treatments, and such materials often lack side effects [5].

Several non-transfusional hemocomponents are available for intralesional injection, including platelet-rich plasma (PRP), plasma rich in growth factors, platelet rich fibrin, platelet lysate, autologous conditioned serum, autologous blood preparations and autologous protein concentrate [7, 9, 22]. Platelet-rich plasma is thought to lead to improvement by the stimulation and acceleration of bone growth, and soft tissue healing [11].

An $85 \mathrm{~kg}$, 9-month-old, filly donkey was referred to the Large Animal Division of Veterinary Teaching Hospital, University of Camerino, for severe, acute onset right hind limb lameness. The filly was hospitalized for possible surgical treatment of a suspected closed fracture of the right tibia.

The general physical condition of the filly was good; however, the right hind limb was maintained in a flexed position. Physical examination revealed swelling and pain in the mid tibial area, lateral and rotational instability, and crepitus at the tibial diaphysis. There was no external bleeding or skin wounds.

Lateral to medial and cranial to caudal radiographic images of the tibia (Fig. 1) showed a severe, comminuted diaphyseal fracture, with oblique and spiral fracture lines and long fissures, and with overriding and smaller fragments. Hematologic values were within normal range.

Preoperative therapy included intravenous flunixin meglumine $(1.1 \mathrm{mg} / \mathrm{kg}$, twice daily), and intramuscular procaine benzylpenicillin $(9,000 \mathrm{UI} / \mathrm{kg})$ and dihydrostreptomycin sulphate $(11.25 \mathrm{mg} / \mathrm{kg})$ once daily, and a surgical osteosynthesis of the tibia was scheduled for the next day.

After premedication with intravenous xylazine $(1.3 \mathrm{mg} / \mathrm{kg})$, general anaesthesia was induced with intravenous ketamine $(2.2 \mathrm{mg} /$ $\mathrm{kg})$ and midazolam $(0.02 \mathrm{mg} / \mathrm{kg})$, and maintained with isoflurane in oxygen. The filly was placed in right lateral recumbency, and the operative site was aseptically prepared.

A craniomedial approach to the diaphysis of the tibia was performed. Bone-holding forceps allowed reduction and temporary stabilization of the fracture. Fixation with multiple lag screws (four 3.5-4.5 mm lag screws) allowed anatomical reconstruction and

*Correspondence to: Tambella, A. M., School of Biosciences and Veterinary Medicine, University of Camerino, Via Circonvallazione, $93 / 95,62024$ Matelica MC, Italy. e-mail: adolfomaria.tambella@unicam.it

(O2017 The Japanese Society of Veterinary Science

This is an open-access article distributed under the terms of the Creative Commons Attribution Non-Commercial No Derivatives (by-ncnd) License. (CC-BY-NC-ND 4.0: https://creativecommons.org/licenses/by-nc-nd/4.0/) 


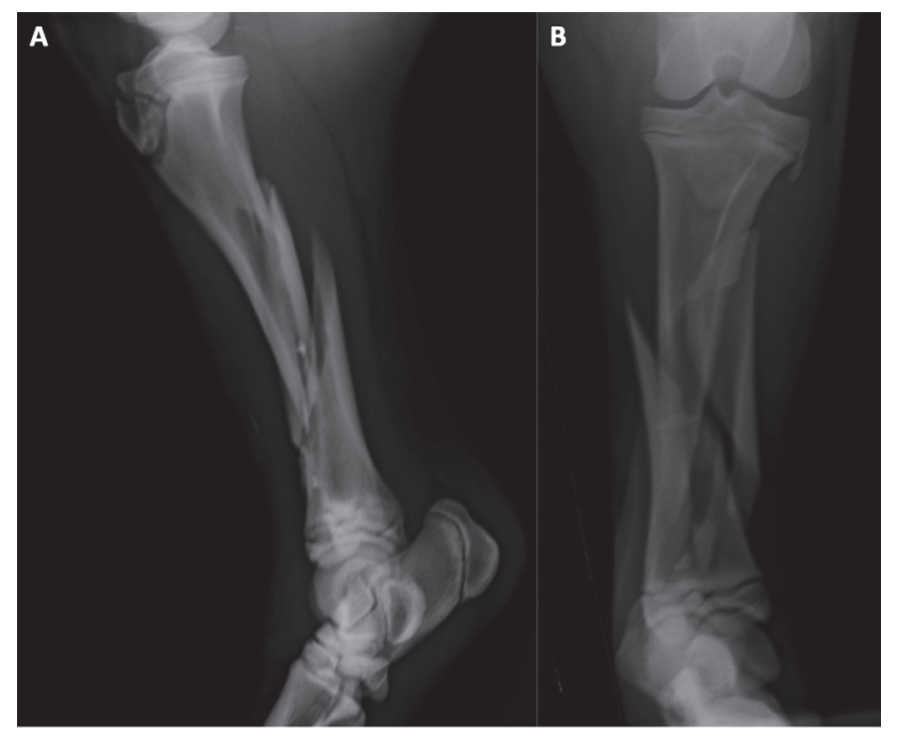

Fig. 1. Lateromedial (A) and craniocaudal (B) images of the tibial fracture.

interfragmentary compression of reducible fragments. Fragments that were small or clearly ischemic were removed, resulting in a moderate bone deficit in the distal portion of the fracture. A neutralization plate with ten holes in an offset arrangement was applied to protect the bone reconstruction (Fig. 2). The plate was suitably shaped to fit the surface of the medial bone cortex. Eight $4.5 \mathrm{~mm}$ cortical bone screws were inserted in neutral position, four cranially and four distally.

At the end of the surgery, the bone alignment and the fragment reduction were satisfactory and confirmed by post-surgery radiographic evaluation; however, immobilization was considered tenacious, despite the limited length of the three most distal screws.

During the early postoperative period, the donkey was able to rise with assistance and was confined in a $2 \times 2$ meter box stall with a non-slip floor. The limb was bandaged from the hoof to mid-thigh using a modified Robert Jones technique. The donkey was immediately weight bearing on the right hind limb. Antibiotic and anti-inflammatory therapy was continued for seven days. Sutures were removed 10 days after surgery.

The first radiographic evaluation was performed 20 days after surgery, and further examinations were performed on a monthly basis, for a total follow-up of six months.

The day 20 radiographs showed good axial alignment of the tibia and maintenance of the position of the implants. However, on the craniocaudal images, a large bone gap was evident. Despite good clinical condition, no obvious signs of improvement were found at the second radiographic evaluation (day 50), except for slight periosteal new bone formation, without a visible interfragmentary callus (Fig. 3). Due to delayed bone consolidation, percutaneous injection of platelet-rich plasma was planned for the next day.

Autologous whole blood $(50 \mathrm{~m} l)$ was withdrawn from the jugular vein. Acid citrate dextrose solution (ACDA, Salf SpA, Canate Sotto, Bergamo, Italy) was added at a ratio of $1: 9$ as an anticoagulant. Additionally, to extract thrombin, $10.5 \mathrm{~m} l$ whole blood was collected in sodium citrate tubes (3.8\%; Vacuette Tube, Greiner Bio-One GmbH, Kremsmünster, Austria).

For density separation of blood components, the $50 \mathrm{~m} l$ specimen was centrifuged (Rotina 46R, Hettich, Milan, Italy) at 350 units of gravitational force $(\times g)$ for $20 \mathrm{~min}$. The plasma and the buffy coat were centrifuged again at $900 \times g$ for 15 min to separate the platelet pellet, in the bottom layer, from the platelet poor plasma (PPP) in the supernatant. The platelet pellet was resuspended in PPP to obtain $10 \mathrm{~m} l$ of PRP. The cell count, performed automatically (Cell Dyn 3500R, Abbott, Wiesbaden, Germany), showed a significant increase (4.34 fold) in platelet concentration in the PRP $\left(1638 \times 10^{6}\right.$ cells $\left./ \mathrm{m} l\right)$ when compared to whole blood $(377 \times$ $10^{6}$ cells $\left./ \mathrm{m} l\right)$.

Thrombin was obtained by mixing the autologous plasma fraction and $10 \%$ calcium gluconate $(446 \mathrm{mEq} / \mathrm{lof}$ calcium; Monico $\mathrm{SpA}$, Mestre, Venezia, Italy), at a ratio of $5: 1$, and incubating at $37^{\circ} \mathrm{C}$ for $30 \mathrm{~min}$, in an air-jacketed $\mathrm{CO}_{2}$ incubator $(\mathrm{NuAire} \mathrm{DH}$ Autoflow, Plymouth, MN, U.S.A.). The clot obtained was compressed, and the thrombin-rich supernatant was collected.

Activation of PRP occurred by mixing the PRP and the thrombin-rich solution (volumetric ratio 8:1) in a Falcon tube (Sterilin Ltd., Newport, U.K.), and gently rotating the tube. These laboratory procedures were performed under aseptic conditions in a laminar flow cabinet (Bicasa, Barnareggio, MB, Italy) following Good Laboratory Practice.

To apply the activated PRP to the tibial surface, the filly was sedated with intravenous detomidine hydrochloride (10 $\mu \mathrm{g} / \mathrm{kg})$. Due to the small amount of tissue between the skin surface and the craniomedial aspect of the diaphysis of the tibia, the plate and the heads of the screws were easily palpated. Palpation, and the simultaneous display of radiographs, allowed for accurate injection of PRP. After routine aseptic skin preparation, $10 \mathrm{~m} l$ of the activated PRP was applied to the tibia by topical percutaneous injection at the cranial edge of the plate, as close as possible, to the large area of the fracture site (Fig. 4). Following the PRP injection, the 


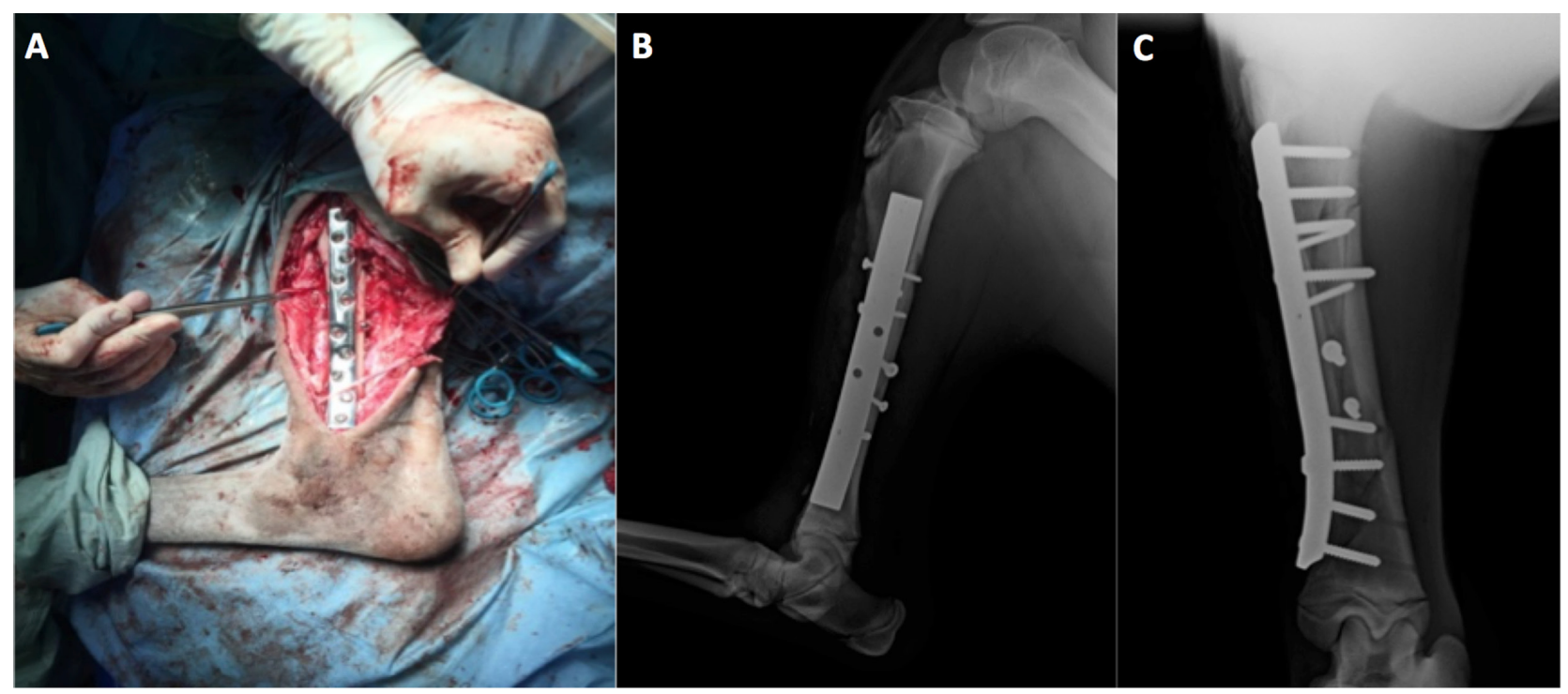

Fig. 2. Intra-operatory image after application of the plate (A) and postoperative lateromedial (B) and craniocaudal (C) projections.

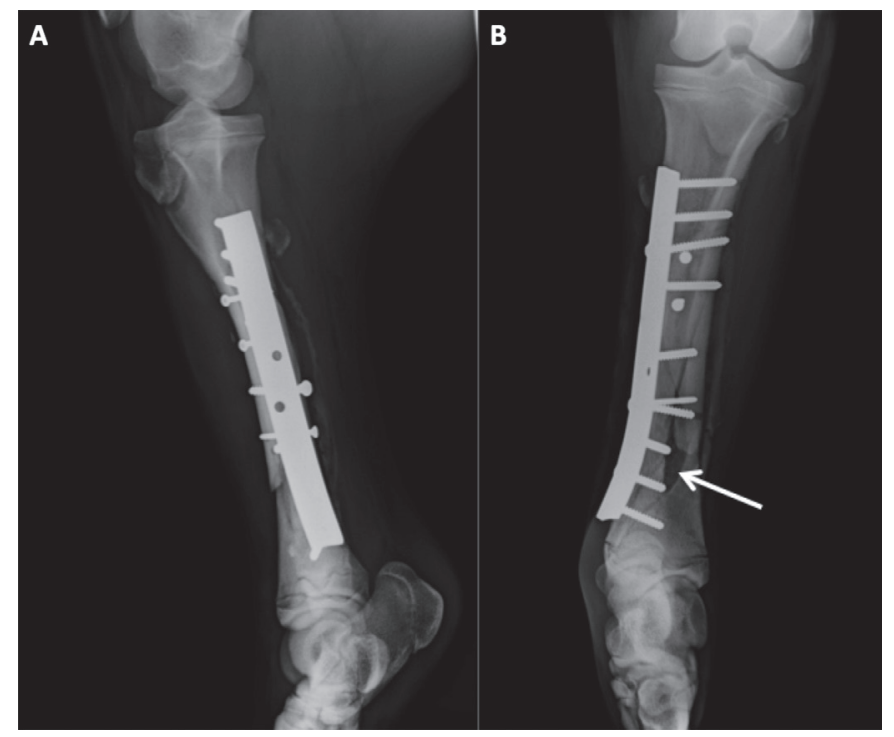

Fig. 3. Lateromedial (A) and craniocaudal (B) images 50 days after the osteosynthesis, note the large bone gap on the distal part of the fracture (arrow).

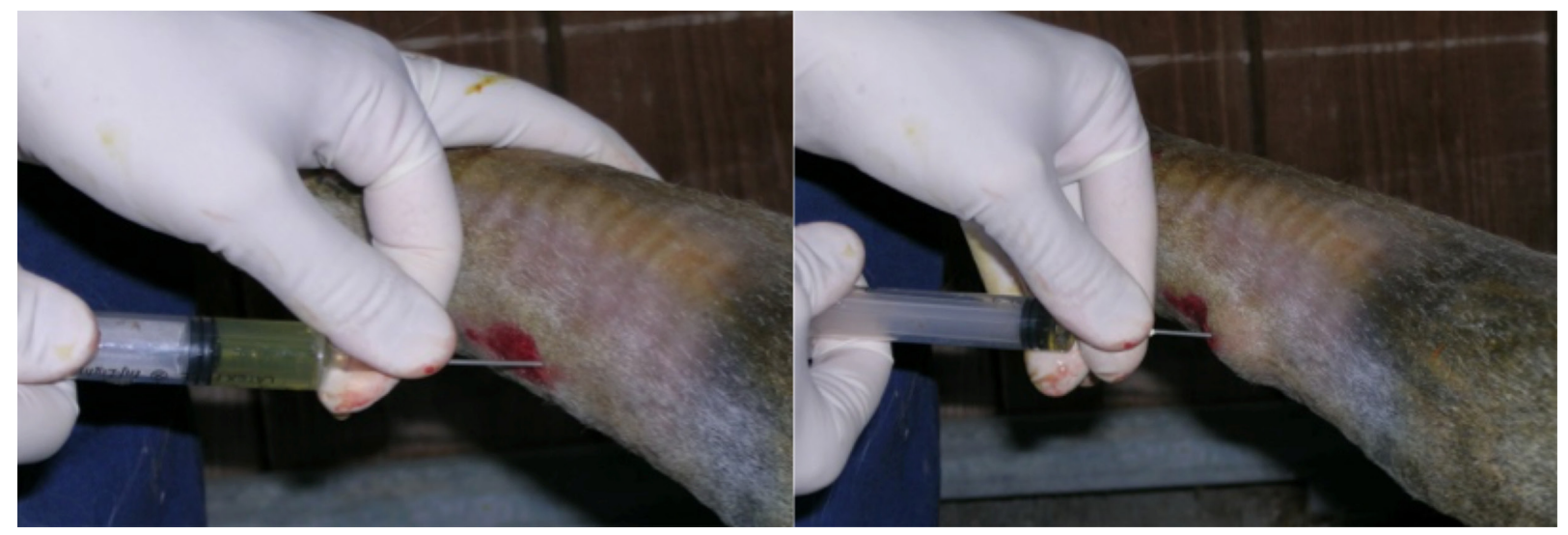

Fig. 4. Percutaneous injection of platelet-rich plasma (PRP) on the craniomedial aspect of the tibial shaft fracture site. The injection was to the cranial edge of the palpable plate. 


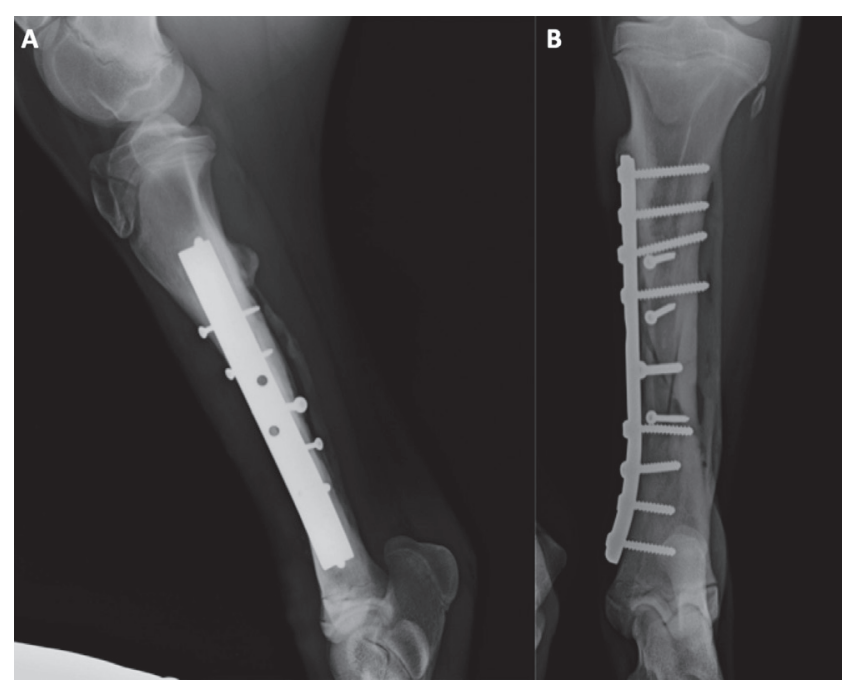

Fig. 5. Lateromedial (A) and craniocaudal (B) images 80 days after osteosynthesis (30 days after the platelet-rich plasma [PRP] injection).

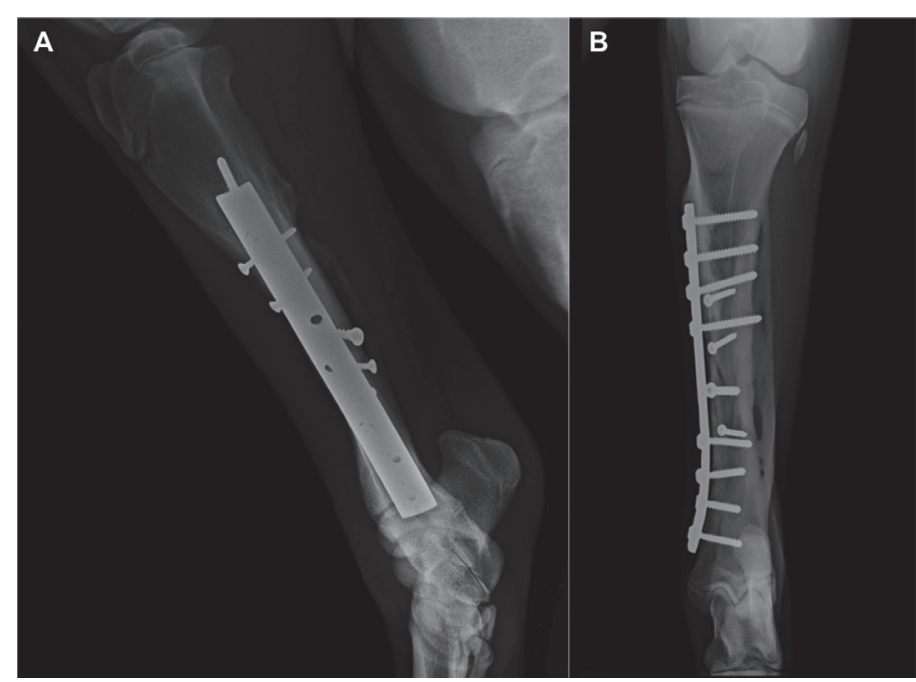

Fig. 6. Lateromedial (A) and craniocaudal (B) images 150 days after osteosynthesis (100 days after the platelet-rich plasma [PRP] injection). Note the progression of healing and filling of the bone gap.

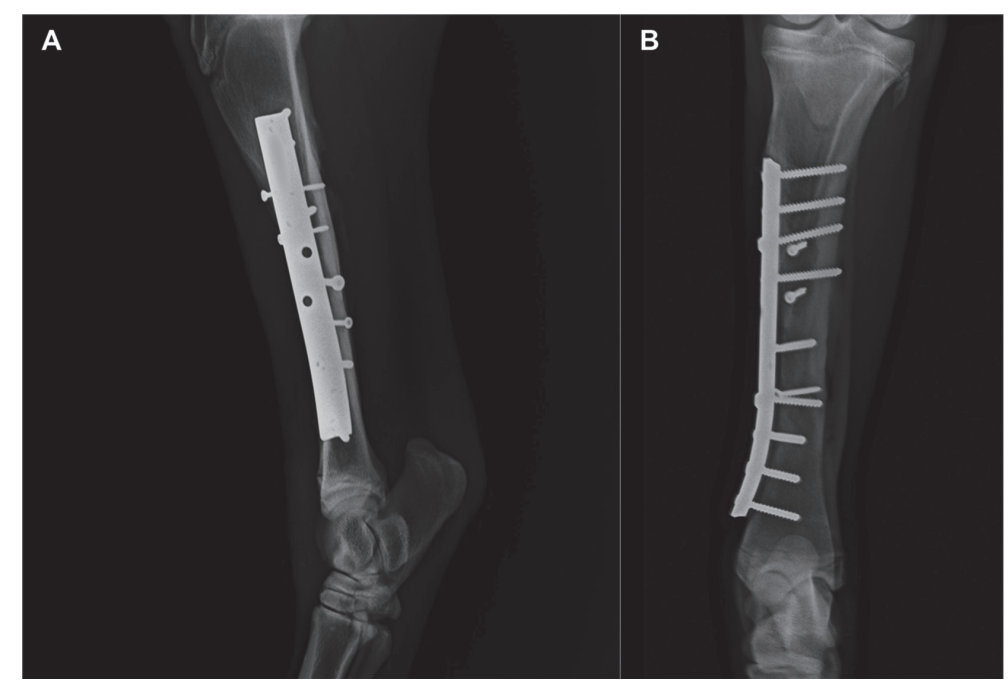

Fig. 7. Lateromedial (A) and craniocaudal (B) images 190 days after osteosynthesis (140 days after the platelet-rich plasma [PRP] injection). Note the radiographic evidence of complete bone healing.

site was not bandaged, and the donkey did not receive local or systemic therapy. The donkey was kept under close observation in a box with non-slip flooring for $48 \mathrm{hr}$. No technical problems occurred during the procedure, and the PRP was well tolerated without apparent side effects.

One month after the PRP injection, improvement in bone consolidation was evident on radiographs (Fig. 5), and no additional treatment was planned. The bone healing continued during the follow up, with progressive filling of the fracture lines and bone gap (Figs. 6 and 7). Clinical condition and gait were considered very good. An excellent outcome was obtained, and a favorable prognosis was issued.

The use of non-transfusional hemocomponents for tissue healing has gained increasing popularity for the treatment of musculoskeletal lesions in human and veterinary medicine [5]. Among the hemocomponents, PRP is a good adjunctive therapy for the treatment of orthopedic and soft tissue conditions $[3,6,7,13,17,18,20]$. Non-unions, bone defects, tendinosis and cartilage defects are among musculoskeletal conditions lacking effective treatment modalities, and regenerative medicine may play an important role. Delayed bone union and non-union can result from a gap at the fracture site resulting from bone loss. Platelet rich plasma contains a variety of growth factors released from platelets, which increase vascular growth and have mitogenic effects on mesenchymal stem cells $[2,8,11,14,19]$.

In this case, a number of factors may have contributed to the delay in bone consolidation, including: conformation of the 
fracture, bone gap, high rigidity of the implant and/or a possible, minute instability, resulting from the limited length of the three most distal screws, which had not been placed bicortically. The body weight of the donkey may have contributed to implant stability.

The double step centrifugation method to produce autologous PRP allowed us to easily obtain an applicable product, with a platelet concentration higher than the concentration considered therapeutic [1, 15]. Full recovery of bone consolidation, obtained after PRP therapy, allows us to speculate that the application of autologous PRP was effective in bone healing in this donkey. Clinical research on donkeys needs to be in continual development, since donkeys have different reactions in many conditions when compared to horses [12]. To our knowledge, internal osteosynthesis of long bone fracture is not commonly performed in donkeys [10, 21]; furthermore, scientific literature considering internal osteosynthesis and PRP production and application in donkeys is lacking.

Further clinical reports and studies are needed to increase the rate of orthopaedic surgery in donkeys and to evaluate the therapeutic potential of PRP application in this species.

ACKNOWLEDGMENT. This work was supported by a research grant from the University of Camerino (Fondo di Ateneo per la Ricerca 2014-2015), Italy.

\section{REFERENCES}

1. Argüelles, D., Carmona, J. U., Pastor, J., Iborra, A., Viñals, L., Martínez, P., Bach, E. and Prades, M. 2006. Evaluation of single and double centrifugation tube methods for concentrating equine platelets. Res. Vet. Sci. 81: 237-245. [Medline] [CrossRef]

2. Bielecki, T., Gazdzik, T. S. and Szczepanski, T. 2008. Benefit of percutaneous injection of autologous platelet-leukocyte-rich gel in patients with delayed union and nonunion. Eur. Surg. Res. 40: 289-296. [Medline] [CrossRef]

3. Boswell, S. G., Cole, B. J., Sundman, E. A., Karas, V. and Fortier, L. A. 2012. Platelet-rich plasma: a milieu of bioactive factors. Arthroscopy 28: 429-439. [Medline] [CrossRef]

4. Bramlage, L. R. 2012. Tibia. pp. 1409-1419. In: Equine Surgery. 4th ed. (Auer, J.A. and Stick, J.A. eds.), Saunders Elsevier, St. Louis.

5. Brossi, P. M., Moreira, J. J., Machado, T. S. L. and Baccarin, R. Y. A. 2015. Platelet-rich plasma in orthopaedic therapy: a comparative systematic review of clinical and experimental data in equine and human musculoskeletal lesions. BMC Vet. Res. 11: 98. [Medline] [CrossRef]

6. Burnouf, T., Goubran, H. A., Chen, T. M., Ou, K. L., El-Ekiaby, M. and Radosevic, M. 2013. Blood-derived biomaterials and platelet growth factors in regenerative medicine. Blood Rev. 27: 77-89. [Medline] [CrossRef]

7. Chevalier, X. 2010. Intraarticular treatments for osteoarthritis: new perspectives. Curr. Drug Targets 11: 546-560. [Medline] [CrossRef]

8. Dallari, D., Fini, M., Stagni, C., Torricelli, P., Nicoli Aldini, N., Giavaresi, G., Cenni, E., Baldini, N., Cenacchi, A., Bassi, A., Giardino, R., Fornasari, P. M. and Giunti, A. 2006. In vivo study on the healing of bone defects treated with bone marrow stromal cells, platelet-rich plasma, and freeze-dried bone allografts, alone and in combination. J. Orthop. Res. 24: 877-888. [Medline] [CrossRef]

9. Dohan Ehrenfest, D. M., Rasmusson, L. and Albrektsson, T. 2009. Classification of platelet concentrates: from pure platelet-rich plasma (P-PRP) to leucocyte- and platelet-rich fibrin (L-PRF). Trends Biotechnol. 27: 158-167. [Medline] [CrossRef]

10. Gadallah, S., El-Keiey, M., Amer, M. S. and Shamaa, A. A. 2014. Equine limb fracture: the incidence and management. Minufiya Vet. J. 8: $247-261$.

11. Kawasumi, M., Kitoh, H., Siwicka, K. A. and Ishiguro, N. 2008. The effect of the platelet concentration in platelet-rich plasma gel on the regeneration of bone. J. Bone Joint Surg. Br. 90: 966-972. [Medline] [CrossRef]

12. Laus, F., Spaterna, A., Faillace, V., Veronesi, F., Ravagnan, S., Beribé, F., Cerquetella, M., Meligrana, M. and Tesei, B. 2015. Clinical investigation on Theileria equi and Babesia caballi infections in Italian donkeys. BMC Vet. Res. 11: 100. [Medline] [CrossRef]

13. Lee, K. S., Wilson, J. J., Rabago, D. P., Baer, G. S., Jacobson, J. A. and Borrero, C. G. 2011. Musculoskeletal applications of platelet-rich plasma: fad or future? AJR Am. J. Roentgenol. 196: 628-636. [Medline] [CrossRef]

14. Malhotra, R., Kumar, V., Garg, B., Singh, R., Jain, V., Coshic, P. and Chatterjee, K. 2015. Role of autologous platelet-rich plasma in treatment of long-bone nonunions: a prospective study. Musculoskelet. Surg. 99: 243-248. [Medline] [CrossRef]

15. Mazzucco, L., Balbo, V. and Guaschino, R. 2012. "Reasonable compromise" to define the quality standards of platelet concentrate for nontransfusion use (CPunT). Transfus. Apheresis Sci. 47: 207-211. [Medline] [CrossRef]

16. Nixon, A. J., Watkins, J. P. and Auer, J. A. 1996. Principles of fracture fixation. pp. 63-86. In: Equine Fracture Repair. (Nixon, A. J. ed.), W.B. Saunders Company, Philadelphia.

17. Pichereau, F., Décory, M. and Cuevas, R. G. 2014. Autologous platelet concentrate as a treatment for horses with refractory fetlock osteoarthritis. $J$. Equine Vet. Sci. 34: 489-493. [CrossRef]

18. Roukis, T. S., Zgonis, T. and Tiernan, B. 2006. Autologous platelet-rich plasma for wound and osseous healing: a review of the literature and commercially available products. Adv. Ther. 23: 218-237. [Medline] [CrossRef]

19. Simman, R., Hoffmann, A., Bohinc, R. J., Peterson, W. C. and Russ, A. J. 2008. Role of platelet-rich plasma in acceleration of bone fracture healing. Ann. Plast. Surg. 61: 337-344. [Medline] [CrossRef]

20. Tambella, A. M., Attili, A. R., Dini, F., Palumbo Piccionello, A., Vullo, C., Serri, E., Scrollavezza, P. and Dupré, G. 2014. Autologous platelet gel to treat chronic decubital ulcers: a randomized, blind controlled clinical trial in dogs. Vet. Surg. 43: 726-733. [Medline]

21. Thilagar, S., Ayyappan, S., George, R. S. and Kumaresan, A. 2003. Management of metacarpus fracture by AO/ASIF technique in a donkey. Indian Vet. J. 80: 63-64.

22. Ziltener, J. L., Allet, L., Sclison, P. and Grosclaude, M. 2012. How effective are injections of platelet-rich plasma (PRP) for the treatment of sports injuries: a critical review of the literature. J. Sports Medic. Doping Studie S2: 003. 